\title{
Comparison of Macintosh Laryngoscope and GlideScope $₫$ for Orotracheal Intubation in Children Older Than One Year
}

\section{LEYLA KILINÇ}

Sisli Hamidiye Etfal Egitim ve Arastirma Hastanesi

HACER SEBNEM TURK ( $\sim$ hacersebnem@yahoo.com.tr)

Sisli Hamidiye Etfal Egitim ve Arastirma Hastanesi https://orcid.org/0000-0003-0225-1965

\section{SURHAN CINAR}

Sisli Hamidiye Etfal Egitim ve Arastirma Hastanesi

CANAN TÜLAY ISIL

Sisli Hamidiye Etfal Egitim ve Arastirma Hastanesi

\section{MELTEM KABA}

Sisli Hamidiye Etfal Egitim ve Arastirma Hastanesi

\section{Research Article}

Keywords: Macintosh Laryngoscope, Orotracheal Intubation, Videolaringoscope, Pediatric

Posted Date: December 13th, 2018

DOI: https://doi.org/10.21203/rs.2.100/v1

License: (9) This work is licensed under a Creative Commons Attribution 4.0 International License. Read Full License 


\section{Abstract}

Background: We compared intubation conditions, intubation times, and hemodynamic response with the GlideScope video laryngoscope or the Macintosh direct laryngoscope in children older than one year.

Methods: In total, 80 patients aged 1-12 years, scheduled to undergo elective surgery under general anesthesia with endotracheal intubation were included in a prospective, randomized trial.After standard anesthesia induction, patients were randomized into two groups. The group $\mathrm{G}$ patients $(n=40)$ were intubated with the GlideScope and the group M patients $(n=40)$ were intubated with the Macintosh laryngoscope.Intubation time, number of attempts,Cormack-Lehane score, airway maneuvers,visual analog score were recorded. Hemodynamic variables were recorded before and after anesthesia induction, at intubation, and one,three, and five minutes after intubation.

Results: The demographic data and operation time were similar between the two groups. The intubation time was longer in Group G. The incidence of Cormack-Lehane score 1 was higher in Group $\mathrm{G}$ and that of Cormack-Lehane score 2 was higher in Group M. The hemodynamic parameters were similar between the two groups.

Conclusion: We concluded that the GlideScope video laryngoscope provided better glottis visualization, but prolonged intubation time. No beneficial hemodynamic effect was found with the video laryngoscope.

Keywords: Macintosh Laryngoscope, Orotracheal Intubation, Videolaringoscope, Pediatric

Trial registration: ClinicalTrial.gov, NCT03326882, retrospectively registered, October 31, 2017

\section{Background}

Airway anatomy and physiology vary among adults and children and are major factors in increasing morbidity and mortality rates during tracheal intubation. The Macintosh laryngoscope remains the most commonly used tracheal intubation device among children [1]. Many devices exist for difficult intubation such as the video laryngoscope (GlideScope [GVL]; Verathon Medical, Bothell, WA, Storz, Airtraq) and the fiberoptic bronchoscope [2,3] Fiberoptic bronchoscopes and supraglottic airway devices are useful techniques for difficult pediatric intubation [4].

GVL has been designed specifically for difficult intubation cases, and in many adult studies it has been shown to reduce airway trauma and, therefore, assist significantly in glottis visualization [5-8]. Few prospective studies exist on difficult elective intubation in children and most of them are designed with simulation devices for mannequins [9-15].

The GVL allows for tutoring pediatric intubation in education clinics since it is able to record visuals, and enthusiasm for video laryngoscopy has risen among pediatric anesthesiologists. The GVL provides a 
better laryngeal view as its blade has a digital camera at the distal end in a $60^{\circ}$ angle. It is available in various pediatric sizes for tracheal intubation, but it does increase the duration of the intubation $[5,6]$.

We performed GVL at our clinic. In this study, we compared the intubation quality and hemodynamic effects of the GVL and Macintosh laryngoscope in children older than one year.

\section{Methods}

Institutional medical ethic committee approval was received (SEEAH, 606-16.02.2016). Then the study was recorded on at http:clinicaltrials.gov (NCT03326882). After obtaining written informed consent from each patient's guardian, 80 patients aged 1 to 12 years (American Society of Anesthesiologists [ASA] physical status I-II), scheduled to undergo elective surgery under general anesthesia with endotracheal intubation, were included in a prospective, single-blinded, randomized trial. The exclusion criteria were risk of pulmonary aspiration, difficult intubation, craniofacial malformation, emergency surgery, cardiovascular disease, respiratory disease, and hemodynamic instability.

Patients were medicated orally 1 hour preoperatively with midazolam $(0.5 \mathrm{mg} / \mathrm{kg}$; maximum dosage, 15 $\mathrm{mg})$. Demographic data, including age (year), weight $(\mathrm{kg})$, height $(\mathrm{cm})$, sex, ASA status, and operation durations (minutes), were recorded. Standard monitoring was established in the operating room with peripheral oxygen saturation, noninvasive arterial pressure, and electrocardiography (Cardiocap II; Datex, Helsinki, Finland). Anesthesia was induced with an inhalational $8 \%$ sevoflurane oxygen-air mixture. An intravenous line was applied, $1-2 \mathrm{mqr} / \mathrm{kg}$ fentanyl and $0.6 \mathrm{mg} / \mathrm{kg}$ rocuronium were administered. From a list of random numbers, instructions for randomization were prepared in sealed envelopes for each patient before the start of the study. Patients were allocated to one of two groups for intubation: Group G, using the GVL $(n=40)$, and group M, using the Macintosh laryngoscope $(n=40)$.

In group G, the GVL 2 (1.8-10.0 kg) and GVL 3 (10 years-adult) blades were used. In group M, sizes 1 (infants and small children), 2 (older children), and 3 (adolescents) blades were used depending on the patient weight based on the manufacturer's guidelines. All intubations were performed using a tracheal tube reinforced with a similarly shaped, malleable stylet. The intubations were performed by the same anesthetists who had used the GVL more than 50 times and were also skilled in conventional direct laryngoscopy.

Intubation time (IT) was defined as the time from the end of preoxygenation (mask taken from the face) to the first detection of end-tidal $\mathrm{CO}_{2}$. IT included the time between attempts. Attempt numbers were recorded. If more than one attempt was required, the patient received mask ventilation between attempts. More than three attempts were not allowed, and were considered as failure of intubation and excluded from the study. Before insertion of the tube into the trachea, the Cormack-Lehane grade of laryngeal views was recorded in all groups.

Airway maneuvers (posterior, superior, and lateral pressure on the larynx, and external laryngeal manipulation, which allowed passage of the tracheal tube during tracheal intubation) were recorded. The 
visual analog scale (VAS; 0 , worse-10, best) was scored by the anesthesiologist after intubation and recorded.

Hemodynamic variables (heart rate [HR], mean arterial pressure [MAP], and blood oxygen saturation level $\left[\mathrm{SpO}_{2}\right]$ ) were observed continuously and recorded before and after anesthesia induction, at intubation, and one, three, and five minutes after intubation by an anesthesiologist who was unaware of this study.

Peripheral oxygen saturations under $90 \%$ were not allowed and these patients were excluded from the study. Bradycardia and hypotension $20 \%$ under baseline were treated with atropine 0.01 to $0.03 \mathrm{mg} / \mathrm{kg} \mathrm{IV}$ and ephedrine $0.2 \mathrm{mg} / \mathrm{kg} \mathrm{IV}$, respectively.

At the end of the operation, inhalational anesthetic agents (sevoflurane and nitrous oxide) were discontinued, and the patient was given $100 \% \mathrm{O}_{2}$. Residual neuromuscular blockade was reversed with injection of neostigmine $(40 \mu \mathrm{g} / \mathrm{kg})$ and atropine $(0.01 \mathrm{mg} / \mathrm{kg})$, tracheal tubes were removed, and the patient transferred to the pediatric acute care unit.

A sample size of 39 in each group for this study at a one-tailed a level of 0.05 was determined to have 95\% power. Statistical analysis was performed with SPSS for Windows, version 15.0 (SPSS, Inc., Chicago, IL, USA). Descriptive statistics were given as number and percentage for categorical variables, and as average, standard deviation, minimum, maximum, and median for numeric variables. Comparison of the two independent groups was performed with Student's $t$-test and the Mann-Whitney $U$ test when the numeric variables did and did not meet the normal distribution requirement, respectively. The rate of the categorical variable between the groups was tested with the chi-squared test. The statistical a significance level was assumed as $P<0.05$.

\section{Results}

A total of 80 patients completed the study. There were no differences in demographic variables and operation times between the two groups (Table 1).

Intubation time was measured as $32,3 \pm 12,9(10,5-64)$ seconds for Group $G$ and $15.7 \pm 6,3(9,1-45)$ seconds for Group M. The IT in Group G was significantly longer than that in Group M $(P<0.001$; Table 2).

In Group G, 36 patients were intubated on the first attempt and four on the second attempt, compared to 31 and nine, respectively, in Group $M$ (not significantly different, $P>0.05$ ). Cormack-Lehane score was 1 in 35 and 25 patients in Groups $G$ and $M$, respectively (statistically significant difference, $P<0.029$ ). Cormack-Lehane score was 2 in five and 13 patients, respectively (statistically significant difference, $P<$ 0.0162 ). VAS score was $7.87 \pm 0.9$ and $8.1 \pm 0.87$, respectively (not significantly different). The number of airway maneuvers was not statistically different between the two groups $(P>0.05$; Table 2$)$. 
No significant differences were found in $\mathrm{HR}, \mathrm{SpO}_{2}$, and MAP measurements between the groups at any time $(P>0.05$; Tables 3-5).

\section{Discussion}

In this study, the GVL provided a better view of the glottis, but a prolonged time to intubation in children older than 1 year with a normal airway. There were no beneficial hemodynamic effects of the use GVL compared to that of the Macintosh direct laryngoscope.

Difficult intubation frequency is rarer in children than adults, but children have shown airway differences and faster oxygen consumption because they are more vulnerable to desaturation. Thus, intubation in children must be performed more cautiously. Because of the anatomic differences in the airway and lack of information required to enable evaluation of difficult airways in the preoperative period, difficult laryngoscopy and intubation may be important reasons for preoperative morbidity. Despite the recent developments in equipment and information related to management of airways in children, endotracheal intubation with conventional laryngoscopy remains the golden standard in protection of airways [1] .

The use of video laryngoscopes in children with difficult intubation has increased in recent years (16). However, there are no sufficient data showing that GVL offers an advantage over direct laryngoscopy in the management of difficult airways in children [4,9-12].

Many studies have compared the GVL with other video laryngoscopy techniques $[4,16,17]$. Several of these studies have been applied to cardiopulmonary resuscitation mannequins or mannequins developed for difficult airway simulation, but none of the video laryngoscopy techniques has a clear advantage over others [14,15]. Riveros et al. [4] compared direct laryngoscopy with the Macintosh blade, GVL, and True View PCD in 134 children from newborn to 10 years old and found that direct laryngoscopy provided the best images, whereas True View PCD had the longest IT. They recommended restriction of use of video laryngoscopy techniques in patients expected to have difficult airways. Kim et al. [12] compared GVL with the Macintosh blade in 203 children and they obtained a view with GVL that was similar to or better than the view obtained with direct laryngoscopy. In the GVL group, $62 \%$ of the patients had a Cormack-Lehane Score $>1$. Furthermore, the number of retried intubations was greater in the GVL group. In the other study of children with a Cormack-Lehane Score $>3$, the GVL was compared to the direct laryngoscope in terms of improvement of laryngoscopic image. Also, image effectiveness of the blade size used was evaluated for GVL. These investigators found that GVL enhanced visualization in difficult airways in children compared to direct laryngoscopy and GVL with a small-sized blade [9]. In their meta-analysis, which included 14 prospective randomized studies comparing different video laryngoscopy techniques to direct laryngoscopy in children, Sun et al. [18] showed that video laryngoscopy enhanced glottis visualization but extended the IT. We found the Cormack-Lehane score to be 1 and 2, consequently in groups G (87.5\% and $12.5 \%$, respectively) and $M(62.5 \%$ and $32.5 \%$, respectively). We found a better glottis view with the $\mathrm{GVL}$, although satisfactory glottis views were obtained in both groups. 
In a pilot study of 18 children known to have difficult intubation, Armstrong et al. [10] found optimal visibility at 20 seconds with direct laryngoscopy and 26 seconds with GVL. Fiadjoe et al. [11] compared direct laryngoscopy with the Miller blade to GVL in 60 newborns and infants with normal airway anatomy and found similar ITs and performances. They obtained better and faster glottis views in the GVL group, but a longer canalization time compared to that in the direct laryngoscopy group. The IT was 22.6 seconds in the GVL group and 21.4 seconds in the direct laryngoscopy group, and the canalization time was 14.3 and 8.5 seconds, respectively. Another prospective study with the highest number of cases measured IT as 36 and 23.8 seconds, respectively. They found that the IT in the GVL group was longer [12]. We found a longer IT in the GVL group, as in other similar studies performed on children. We measured the IT as 16 and 32 seconds in the direct laryngoscopy and GVL groups, respectively. For successful intubation, visualization of the glottis and insertion of an endotracheal tube are needed. With GVL intubation, visualization is good but the endotracheal tube insertion time is longer than that for direct laryngoscopy. The adult size GVL has the same original style GlideRite curve with the GVL blade. For children, the GlideRite single-use stylet (small) may also possibly be used, but we opted to use the conventional malleable stylet. Moreover, the GVL monitor is located against the laryngoscopist and this would be a more challenging intubation with a prolonged IT. The studies show that people who use video laryngoscopy can quickly learn fiberoptic laryngoscopy. The technique is useful for pediatric intubation education [19].

According to the VAS score, we did not find any superiority for ease of intubation as in the literature [2022].

A hemodynamic response develops based on the pain caused by intubation and laryngoscopy. Increased MAP and HR are observed based on catecholamine secretion [23]. Maassen et al. [24] studied adults (ASA II-III) and found that the increase in HR and systolic blood pressure with use of video laryngoscopy is lower compared to that with the use of direct laryngoscopy. Li et al. [25] compared GVL, fiberoptic bronchoscopy, and direct laryngoscopy for nasal intubation in terms of hemodynamic changes and found that the best response was from the GVL group. Abdelgawad et al. [26] compared different video laryngoscopy methods to direct laryngoscopy in terms of hemodynamic response and found no differences in cardiac output, stroke volume index, HR, and systolic-diastolic blood pressure arterial values in normotensive patients. We found no statistically significant differences between the groups at any time.

\section{Conclusions}

In summary, better glottis views were obtained with the GVL. However, intubation takes longer. There was no superiority for orotracheal intubation in children older than one year between the Macintosh laryngoscope and the GVL.

\section{Abbreviations}


ASA: American Society of Anesthesiologists

HR: Heart rate

IT: Intubation time

MAP: Mean arterial pressure

VAS: Visual analog scale

\section{Declarations}

\section{Ethics approval and consent to participate}

This prospective study was approved by the Ethics Committee of Sisli Hamidiye Etfal Education and Research Hospital (SEEAH/606-16.02.2016) ; verbal and written informed consent was obtained from the parents of all children participating in the study.

\section{Consent for publication}

Not applicable.

\section{Availability of data and materials}

The datasets used or analysed during the current study are available from the corresponding author upon reasonable request.

\section{Competing interests}

The authors declare that they have no competing interests.

\section{Funding}

Financial support was provided by departmental sources.

\section{Authors' contributions}

LK designed the study, collected data and wrote the manuscript.HST and SC collected data and performed statistical analyses.CTI and SC wrote the manuscript and assisted with the statistical analyses.HST and MK collected data. MK performed the surgical interventions, reviewed the manuscript and provided the final approval of the manuscript. All authors read and approved the final manuscript.

\section{Acknowledgements}

The authors thank all the members of the pediatric surgery team for their support. 


\section{References}

1) Holm-Knudsen RJ, Rasmussen LS. Paediatric airway management: basic aspects. Acta Anaesthesiol Scand. 2009;53:1-9.

2) Niforopoulou P, Pantazopoulos I, Demestiha T, Koudouna E, Xanthos T.Video-laryngoscopes in the adult airway management: a topical review of the literature. Acta Anaesthesiol Scand. 2010;54:1050-61.

3) Kovatsis PG: Continuous ventilation during flexible fiberscopic-assisted intubation via supraglottic airways. Paediatr Anaesth. 2016;26:457-8.

4) Riveros R, Sung W, Sessler DI, Sanchez IP, Mendoza ML, Mascha EJ, et al. Comparison of the Truview PCDTM and the GlideScope $(\mathrm{H})$ video laryngoscopes with direct laryngoscopy in pediatric patients: a randomized trial. Can J Anaesth. 2013;60:450-7.

5) Cooper RM. Use of a new videolaryngoscope (GlideScope) in the management of a difficult airway. Can J Anaesth. 2003;50:611-3.

6) Lim TJ, Lim Y, Liu EH. Evaluation of ease of intubation with the GlideScope or Macintosh laryngoscope by anaesthetists in simulated easy and difficult laryngoscopy. Anaesthesia. 2005;60:180-3.

7) Cooper RM, Pacey JA, Bishop MJ, McCluskey SA. Early clinical experience with a new videolaryngoscope (GlideScope) in 728 patients. Can J Anaesth. 2005;52:191-8.

8) Griesdale DE, Liu D, McKinney J, Choi PT. Glidescope® videolaryngoscopy versus direct laryngoscopy for endotracheal intubation: asystematic review and meta-analysis. Can J Anaesth. 2012;59:41-52.

9) Lee JH, Park YH, Byon HJ, Han WK, Kim HS, Kim CS, et al. A comparative trial of The GlideScope(R) video laryngoscope to direct laryngoscope in children with difficult direct laryngoscopy and an evaluation of the effect of blade size. AnesthAnalg. 2013;117:176-81.

10) Armstrong J, John J, Karsli C. A comparison between the GlideScope Video Laryngoscope and direct laryngoscope in paediatric patients with difficult airways a pilot study. Anaesthesia. 2010;65:353-7.

11) Fiadjoe JE, Gurnaney H, Dalesio N, Sussman E, Zhao H, Zhang X, et al. A prospective randomized equivalence trial of the GlideScopeCobalt ${ }^{\circledR}$ video laryngoscope to traditional direct laryngoscopy in neonates and infants. Anesthesiology. 2012;116:622-8.

12) Kim JT, Na HS, Bae JY, Kim DW, Kim HS, Kim CS, et al. GlideScope video laryngoscope: a randomized clinical trial in 203 paediatric patients. Br J Anaesth. 2008;101:531-4.

13) Donoghue A, Hsieh TC, Nishisaki A, Myers. Tracheal intubation during pediatric cardiopulmonary resuscitation: A videography-based assessment in an emergency department resuscitation room. Resuscitation. 2016;99:38-43. 
14) Hippard HK, Kalyani G, Olutoye OA, Mann DG, Watcha MF. A comparison of the Truview PCD and the GlideScope Cobalt AVL video-laryngoscopes to the Miller blade for successfully intubating manikins simulating normal and difficult pediatric airways. PaediatrAnaesth. 2016;26:613-20.

15) Fiadjoe JE, Hirschfeld M, Wu S, Markley J, Gurnaney H, Jawad AF, et al. A randomized multiinstitutional crossover comparison of theGlideScope ${ }^{\circledR}$ Cobalt Video laryngoscope to the flexible fiberoptic bronchoscope in a Pierre Robin manikin. PaediatrAnaesth. 2015;25:801-6.

16) Wald $S$, Keyes M, Brown A. Pediatric video laryngoscoperescue for a difficult neonatal intubation. Paediatr Anaesth. 2008;18:790-2.

17) Liu KP, Li CH, Xue FS. Comparison between the Truview PCD ${ }^{T M}$ or the GlideScope ${ }^{\circledR}$ video laryngoscope and direct laryngoscopy for tracheal intubation in pediatric patients.Can J Anaesth. 2013;60:735-6.

18) Sun Y, Lu Y, Huang Y, JiangH. Pediatric video laryngoscope versus direct laryngoscope: a metaanalysis of randomized controlled trials. PaediatrAnaesth. 2014;24:1056-65.

19) Lees M, Seal RF, Spady D, Csanyi-Fritz Y, Robinson JL. Randomized trial of success of pediatric anesthesiologists learning to use two video laryngoscopes. PaediatrAnaesth. 2013;23: 435-9.

20) Das B, Samanta A, Mitra S, Jamil SN. Comparative evaluation of Airtraq ${ }^{\text {TM }}$ optical Laryngoscope and Miller's blade in paediatric patients undergoing elective surgery requiring tracheal intubation: $A$ randomized, controlled trial. Indian J Anaesth. 2017;61:326-31.

21) Madziala M, Smereka J, Dabrowski M, Leung S, Ruetzler K, Szarpak L. Eur A comparison of McGrath MAC $\AA$ and standard direct laryngoscopy in simulated immobilized cervical spine pediatric intubation: a manikin study. J Pediatr. 2017;176:779-86.

22) Hurford DM, White MC. A comparison of the Glidescope and Karl Storz DCl videolaryngoscopes in a paediatric manikin..Anaesthesia. 2010;65:781-4.

23) Kovac AL. Controlling the hemodynamic response to laryngoscopy and endotracheal intubation. J ClinAnesth. 1996;8:63-79.

24) Maassen RL, Pieters BM, Maathuis B, Serroyen J, Marcus MA, Wouters $P$, et al. Endotracheal intubation using videolaryngoscopy causes less cardiovascular response compared to classic direct laryngoscopy, in cardiac patients according a standard hospital protocol. Acta Anaesthesiol Belg. 2012;63:181-6.

25) Li XY, Xue FS, Sun L, Xu YC, Liu Y, Zhang GH, et al. Comparison of hemodynamic responses to nasotracheal intubations with GlideScope video-laryngoscope, Macintosh direct laryngoscope, and fiberoptic bronchoscope. ZhongguoYiXue Ke Xue YuanXueBao. 2007;29:117-23. 
26) Abdelgawad AF, Shi QF, Halawa MA, Wu ZL, Wu ZY, Chen XD, et al. Comparison of cardiac output and hemodynamic responses of intubation among different videolaryngoscopies in normotensive and hypertensive patients. J HuazhongUnivSciTechnologMedSci. 2015;35:432-8.

\section{Tables}

Table I. Demographic variables and operation time

$$
\text { Group M }(n=40) \quad \text { Group G }(n=40) \quad P
$$

$\begin{array}{lccc}\text { Age (year) } & 5.24 \pm 2.11 & 5.07 \pm 2.56 & 0.652 \\ \text { Height }(\mathrm{cm}) & 120.2 \pm 13.1 & 118.6 \pm 17.3 & 0.503 \\ \text { Weight }(\mathrm{kg}) & 22.25 \pm 9.1 & 20.47 \pm 8.8 & 0.359\end{array}$

ASA Status (I/II) $(n / \%) \quad(28 / 12)(70 \% / 30 \%) \quad(24 / 16)(60 \% / 40 \%) \quad 0.345$

$\operatorname{Sex}(\mathrm{M} / \mathrm{FM})(n / \%) \quad(31 / 9)(77.5 \% / 22.5 \%) \quad(29 / 11)(72.5 \% / 27.5 \%) \quad 0.747$

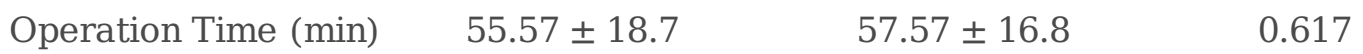

Mean \pm SD. $P<0.05$

Table II. Intubation characteristics

$$
\text { Group M }(n=40) \quad \text { Group G }(n=40) \quad P
$$

Time to intubation (s)

$15.7 \pm 6.33 \quad 32.3 \pm 12.9$

0.0011

Intubation attempts $(n / \%)$ 
Cormack-Lehane ( $n / \%)$
1
$25(62.5 \%)$
35 (87.5\%)
0.0290
2
$13(32.5) \%)$
5 (12.5\%)
3
$2(5 \%)$
0
4
0
0

0.0162

Airway maneuvers ( $n$ )

Yes

$12(30 \%)$

13 (32.5\%)

No

$28(70 \%)$

27 (67.5\%)

VAS score

$8.1 \pm 0.87$

$7.87 \pm 0.9$

0.202

Time to intubation, VAS; mean \pm SD

\section{Table III. HR (beats per minute)}

\section{Group M $(\underline{n=40}) \quad$ Group $\mathrm{G}(\underline{n=40})$}

Mean $\pm \mathrm{SD} \quad$ Median Mean $\pm \mathrm{SD} \quad$ Median $\quad P$

$\begin{array}{llllll}\text { Before Anesthesia Induction } \quad 123.8 \pm 21.3 & 125 & 121.9 \pm 16.7 & 120 & 0.654\end{array}$

$\begin{array}{llllll}\text { After Anesthesia Induction } & 114 \pm 21.211 & 6.5 & 114.4 \pm 16.2 & 114.5 & 0.862\end{array}$

$\begin{array}{llllll}\text { Intubation } & 132.9 \pm 17.1 & 130 & 126.1 \pm 19.1 & 126 & 0.064\end{array}$

After Intubation, 1 min

$128.751 \pm 9.7 \quad 130.5 \quad 128.12 \pm 15.8 \quad 128.5 \quad 0.876$ 
After Intubation, $3 \mathrm{~min}$

After Intubation, $5 \mathrm{~min}$

Mean \pm SD, Median

\section{Table IV. MAP (mmHg)}

\section{Group M $(\underline{n=40})$}

Mean \pm SD Median

Group G $(\underline{n=40})$

Mean \pm S

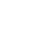

Before Anesthesia Induction

$64 \pm 4.1$

63.5

$64.05 \pm 4.7$

64.5

0.9602

After Anesthesia Induction

$62.7 \pm 4.1$

62.5

$62.9 \pm 4.8$

63.5

0.8232

Intubation

$69.2 \pm 1.4$

66.5

$68.6 \pm 1.69$

67.5

0.7819

After Intubation, 1 min

$64.9 \pm 4.2$

64.5

$64.6 \pm 4.9$

65

0.7722

After Intubation, 3 min

$64.7 \pm 4.2$

64

$64.5 \pm \pm 5.06$

65

0.8482

After Intubation, 5 min

$64.6 \pm 4.07$

64

$64.05 \pm 5.2$

64

0.586

Mean \pm SD, Median

\section{Table V. $\mathrm{SpO}_{2}$}




$$
\text { Mean } \pm \mathrm{SD} \text { Median } \quad \text { Mean } \pm \mathrm{SD} \quad \text { Median } P
$$

$\begin{array}{llllll}\text { Before Anesthesia Induction } & 99.7 \pm 0.6 & 100 & 99.5 \pm 0.7 & 100 & 0.2401\end{array}$

$\begin{array}{llllll}\text { After Anesthesia Induction } & 99.7 \pm 0.6 & 100 & 99.5 \pm 0.7 & 100.2471\end{array}$

$\begin{array}{lllll}\text { Intubation } & 99.4 \pm 0.8 & 100 & 99.5 \pm 0.7 & 100\end{array}$

After Intubation, 1 min

After Intubation, 3 min

After Intubation, 5 min

Mean \pm SD, Median

$$
99.5 \pm 0.8 \quad 100 \quad 99.3 \pm 0.9
$$

$99.5 \pm 0.6 \quad 100$

$99.2 \pm 0.8$

$99 \quad 0.1051$

$99.5 \pm 0.6 \quad 100 \quad 99.2 \pm 0.7$

99

0.0901 